\title{
Genetic Analysis of Longitudinal Trajectory of Clinical Mastitis in First-Lactation Norwegian Cattle
}

\author{
B. Heringstad, ${ }^{\star}$ Y. M. Chang, $†$ D. Gianola, ${ }^{\star} \dagger$ and G. Klemetsdal* \\ *Department of Animal Science, Agricultural University of Norway, P. O. Box 5025, N-1432 Ås, Norway \\ †Department of Animal Sciences, University of Wisconsin, Madison 53706
}

\begin{abstract}
Clinical mastitis records for 36,178 first-lactation daughters of 245 Norwegian Cattle (NRF) sires were analyzed with a Bayesian longitudinal threshold model. For each cow, the period going from $30 \mathrm{~d}$ before calving to $300 \mathrm{~d}$ after calving was divided into 11 intervals of 30 $d$ length each. Absence or presence of clinical mastitis within each interval was scored as "0" or " 1 ", respectively. A Bayesian threshold model consisting of a set of explanatory variables plus Legendre polynomials on time of order four was used to describe the trajectory of liability to clinical mastitis. Heritability ranged between 0.07 and 0.13 before calving, from 0.04 to 0.15 during the first $270 \mathrm{~d}$ after calving, and increased sharply thereafter, as a consequence of the form of the polynomial. Genetic correlations between adjacent days were close to 1 , and decreased when days were further apart. Most genetic correlations were moderate to high. A measure of probability of future daughters contracting clinical mastitis during lactation was computed for each sire. A typical curve had a peak near calving followed by a decrease thereafter. The best sires had a low peak around calving and a low expected probability of mastitis among daughters throughout lactation. Expected fraction of days without mastitis was derived from the probability curves and used for ranking of sires. Rank correlations with genetic evaluations of sires obtained from cross-sectional models were high. However, sire selection was affected markedly, especially at high selection intensity. An advantage of the longitudinal model for clinical mastitis is its ability to take multiple treatments and time aspects into account. (Key words: Bayesian methods, clinical mastitis, genetic evaluation, longitudinal threshold model)
\end{abstract}

Abbreviation key: $\mathbf{C M}=$ clinical mastitis, $\mathbf{E F D}=$ expected fraction of days without mastitis, $\mathbf{N R F}=$ Norwegian Cattle.

\footnotetext{
Received November 28, 2002.

Accepted March 6, 2003.

Corresponding author: Bjørg Heringstad; e-mail: bjorg. heringstad@ihf.nlh.no.
}

\section{INTRODUCTION}

In genetic evaluation of clinical mastitis $(\mathbf{C M})$ in firstlactation Norwegian Cattle (NRF), the trait is treated as binary response in a linear sire model. The score is based on whether or not a cow has had at least one case of veterinary treated CM in the period going from $15 \mathrm{~d}$ before to $120 \mathrm{~d}$ after calving (Heringstad et al., 2000). This clinical mastitis scoring system does not utilize fully the information available from the Norwegian health recording scheme, where all veterinary treatments are registered. For example, cows scored as diseased may have received different number of mastitis treatments during lactation. This implies that such cows are regarded as equally liable to contracting the disease, even though this is not the case. Further, the dates of treatments are known, so it is possible to ascertain at what stage of lactation the disease takes place, and to incorporate this information in a model for genetic evaluation.

There has been an increased interest in using testday (longitudinal) models for genetic analysis of dairy production traits, e.g., see reviews of Jensen (2001) and Swalve (2000). Applications have focused mainly on continuous traits, such as milk yield and SCC, and several random regression models have been discussed in the literature. A different treatment is needed when the longitudinal series consists of discrete responses. Rekaya et al. (1998) suggested a Bayesian approach for analyzing longitudinal binary traits, and presented an application to clinical mastitis in Holsteins, with data consisting of series of binary responses. The advantages of using a longitudinal model over a cross-sectional model for binary data include the ability of taking multiple treatments and time aspects into account, as well as of accounting for environmental effects peculiar to each test-interval. A longitudinal model can give a dynamic description of genetic variation in the course of lactation, although this is highly dependent on the adequacy of the definition of "genotype at time $t$ ". Also, records in progress and "incomplete records" due to culling can be handled in a longitudinal model. See Heringstad et al. (2001) for a description of difficulties involved when handling such records in a cross-sec- 
Table 1. Summary statistics of the dataset.

\begin{tabular}{lr}
\hline First lactation cows, no. & 36,178 \\
Sires, no. & 245 \\
Daughters per sire, mean no. & 148 \\
Herds, no. & 5286 \\
Cows per herd, mean no. & 6.8 \\
Overall mastitis frequency $^{1}, \%$ & 23.3 \\
\hline${ }^{1}$ Overall mastitis frequency = Percentage of cows with at least one \\
record of veterinary treatment of mastitis in the period from 30 d \\
before to 300 d after first calving.
\end{tabular}

tional analysis. A disadvantage, however, is that the longitudinal model is more computationally demanding. This is because more records per animal results in larger datasets and because more parameters usually are needed than in a cross-sectional specification.

In this study, sequences of binary CM records on firstlactation NRF cows were analyzed with a longitudinal threshold model with the following objectives: 1) to examine alternative criteria for ranking and selection purposes, and 2) to compare sire evaluations obtained from the longitudinal model with those from cross-sectional models.

\section{MATERIALS AND METHODS}

\section{Data}

The data were from first-lactation daughters of 245 NRF sires having their first progeny test in 1991 or 1992. Only records of daughters with a first calving in 1990 through 1992, and from herds having at least 5 daughters of any of these test-bulls were kept. The resulting dataset included 36,178 first-lactation cows from 5286 herds. Summary statistics are given in Table 1 . The pedigree file represented 437 males (via relationships through sires and maternal grandsires of the 245 sires above). All cases of veterinary treated CM in firstlactation, from $30 \mathrm{~d}$ before calving to culling, second calving or $300 \mathrm{~d}$ after calving, whichever occurred earlier, were included. About $77 \%$ of the cows did not have CM during first lactation, while $16 \%, 5 \%$, and $2 \%$ had 1,2 , or 3 cases, respectively. Only 315 cows had more than four recorded CM treatments. Within cows with mastitis, the mean number of CM treatments during first lactation was 1.5. For each cow, the period going from $30 \mathrm{~d}$ before calving to $300 \mathrm{~d}$ after first calving was divided into 11 intervals of $30 \mathrm{~d}$ length each. Within each such interval, absence or presence of mastitis was scored as "0" or "1", respectively, based on whether or not the cow had at least one veterinary treatment of CM recorded. Cows culled before $300 \mathrm{~d}$ after calving, were scored also in the interval in which they were culled, irrespectively of the number of completed days
Table 2. Mastitis frequency and cumulative culling rate in the eleven $30 \mathrm{~d}$ periods of first lactation.

\begin{tabular}{llcl}
\hline & $\begin{array}{l}\text { Days } \\
\text { from } \\
\text { Period }\end{array}$ & $\begin{array}{l}\text { Mastitis } \\
\text { frequency }\end{array}$ & $\begin{array}{l}\text { Cumulative } \\
\text { culling }\end{array}$ \\
\hline 1 & -30 to 0 & 4.7 & $\begin{array}{l}\text { rate }{ }^{2}, \% \\
2\end{array}$ \\
1 to 30 & 10.1 & 0 \\
3 & 31 to 60 & 2.2 & 3.6 \\
4 & 61 to 90 & 2.0 & 6.0 \\
5 & 91 to 120 & 1.9 & 7.8 \\
6 & 121 to 150 & 1.7 & 9.8 \\
7 & 151 to 180 & 1.6 & 12.0 \\
8 & 181 to 210 & 1.5 & 14.6 \\
9 & 211 to 240 & 1.5 & 17.4 \\
10 & 241 to 270 & 1.4 & 20.4 \\
11 & 271 to 300 & 1.7 & 23.2 \\
\hline
\end{tabular}

${ }^{1}$ Percentage of cows with at least one case of clinical mastitis during the interval.

${ }^{2}$ Percentage of cows that were culled before the end of the interval.

in the last interval. Cows that were culled and did not have mastitis in the last interval, were scored as "0" even though the period at risk was shorter than $30 \mathrm{~d}$. This would overstate the resistance to mastitis of that cow in that particular period.

Mastitis frequency was $4.7 \%$ and $10.1 \%$ in the first two intervals, respectively, and varied between $1.4 \%$ and $2.2 \%$ in the following 9 intervals (Table 2). If a cow had mastitis within a given interval, the day of treatment was used in the time dependent function (described later); otherwise, the midpoint of the interval was used as time. About $26 \%$ of the cows were culled before $300 \mathrm{~d}$ after calving, and the cumulative culling rate is shown in Table 2. About 6\%, 12\%, and $20 \%$ of the cows were culled prior to 60,150 , and $240 \mathrm{~d}$ of lactation, respectively.

\section{Statistical Model}

The binary CM records were analyzed with a longitudinal version of the standard threshold-liability model (e.g., Gianola, 1982). In a study of Chang (2002), liability to CM was related to stage of lactation using the AliSchaeffer function, the Wilmink function, and Legendre polynomials of order 2, 3, and 4. Model comparison using a pseudo Bayes factor strongly favored the 4th order Legendre polynomial function over all other models. Based on this model selection study a linear longitudinal model with regressions of liability on Legendre polynomials on time up to order four was used. The unobserved liability $(\lambda)$ to $\mathrm{CM}$ was expressed as:

$$
\lambda_{i j k l m t}=y_{i}+h_{j}+p_{k}+\varphi_{4}^{\prime}(t) \mathbf{a}_{l}+\varphi_{4}^{\prime}(t) \mathbf{s}_{m}+e_{i j k l m t}
$$

where 

$\lambda_{i j k l m t}=$ liability to CM at time $t$ of daughter $k$ of sire $m$ calving in year $i$, herd $j$, and age $\times$ season class $l$;
$y_{i}=$ effect of year of calving $i(i=1990,1991$, 1992);
$h_{j}=$ effect of herd $j(j=1,2, \ldots, 5286)$;
$p_{k}=$ "cow-specific" effect common to all inter- vals $(k=1,2, \ldots, 36,178)$;
$\mathbf{a}_{1}=5 \times 1$ vector of "fixed" regressions by age $\times$ season of calving class $l$. There were 12 age $\times$ season classes, resulting from com- bining 3 age classes $(<24,24$ to 27 , and $>27 \mathrm{mo}$ ) with 4 season levels (March-May, June-August, September-November, and December-February);
$\mathbf{s}_{\mathrm{m}}=5 \times 1$ vector of random regressions peculiar to sire $m(m=1,2, \ldots, 437)$;
$\varphi_{4}(t)=$ incidence vector containing Legendre polynomials on time up to order 4 relating time $t$ to the liability of a cow at a specific time; and
$\mathrm{e}_{\mathrm{ijklmt}}=$ residual effect, which follows a normal process $\mathrm{N}(0,1)$.

The common "cow-specific" effect, $p_{k}$, accounts for covariances between liabilities in different periods, assuming a constant correlation between periods. Note that $p_{k}$ includes permanent environmental effects and genetic effects other than those accounted for in the "transmitting ability at time $t$ " of the sire of the cow, which is $\varphi_{4}^{\prime}(t) \mathbf{s}_{\mathbf{m}}$. The variance of the residual distribution was assumed constant from period to period, and set equal to 1 .

\section{Bayesian Analysis}

Prior distributions. Independent proper uniform priors were assumed for each of the year effects and for the "fixed" regressions by age $\times$ season classes:

$$
\begin{gathered}
p\left(y_{i}\right) \sim U\left(y_{\min }, y_{\max }\right) \\
p\left(a_{l, o}\right) \sim U\left(a_{\min }, a_{\max }\right)
\end{gathered}
$$

where $l=1,2, \ldots, 12$ and $o=0,1, \ldots, 4$. For example $a_{3,0}$ denotes the random intercept of the regression function for the third age $\times$ season class. Hyperparameter values were $y_{\min }=a_{\min }=-99$ and $y_{\max }=a_{\max }=99$. The herd $\left(h_{j}\right)$ and "cow-specific" $\left(p_{k}\right)$ effects were assigned independent normal priors with means zero and unknown variances. The prior distributions were:

$$
p\left(h_{j} \mid \sigma_{h}^{2}\right) \sim N\left(0, \sigma_{h}^{2}\right)
$$

$$
p\left(p_{k} \mid \sigma_{p}^{2}\right) \sim N\left(0, \sigma_{p}^{2}\right)
$$

where $\sigma_{h}^{2}$ is the variance between herds, and $\sigma_{p}^{2}$ is the variance of "cow-specific" effects. Independent scaled inverse Chi-square prior distributions were assumed for the variances of herd and "cow-specific" effects:

$$
\begin{aligned}
& p\left(\sigma_{h}^{2}\right) \sim \nu_{h} \tau_{h} \chi_{\nu_{h}}^{-2} \\
& p\left(\sigma_{p}^{2}\right) \sim \nu_{p} \tau_{p} \chi_{\nu_{p}}^{-2}
\end{aligned}
$$

where $\nu_{h}=\nu_{p}=2$ are the degrees of freedom parameters, and $\tau_{h}=\tau_{p}=0.1$ are the scale parameters. A multivariate-normal prior distribution was used for the sire regression effects, as follows:

$$
\mathbf{s}_{m} \mid \mathbf{G} \sim N(\mathbf{0}, \mathbf{G})
$$

where $\mathbf{s}_{\mathrm{m}}$ is the $5 \times 1$ vector of regression coefficients for sire $m$, and $\mathbf{G}=\left\{g_{i j}\right\}, i, j=0,1, \ldots, 4$, is the $5 \times 5$ covariance matrix of the sire regression coefficients, assumed common to all sires. Letting $\mathbf{s}=\left[\mathbf{s}_{1}^{\prime}, \mathbf{s}_{2}^{\prime}, \ldots, \mathbf{s}_{437}^{\prime}\right]^{\prime}$, where 437 is the number of sires in the pedigree, the joint prior distribution of all regression coefficients for all sires was:

$$
\mathbf{s} \mid \mathbf{G} \sim N(\mathbf{0}, \mathbf{A} \otimes \mathbf{G})
$$

where $\mathbf{A}$ is a $437 \times 437$ matrix of additive relationships between sires. The matrix $\mathbf{G}$ was assigned an inverse Wishart prior distribution:

$$
p(\mathbf{G}) \sim I W\left(\nu_{\mathrm{g}}, \mathbf{V}_{g}\right)
$$

where $\nu_{g}$ is the degrees of freedom parameter, and $\mathbf{V}_{g}$ is the scale matrix.

Posterior distributions. The joint posterior density of all the unknowns is proportional to the product of the densities in [1] through [8], times the conditional distribution of the observations. The latter was product Bernoulli over intervals and cows, and with a probability of response (mastitis) peculiar to each cow and each interval. Draws from the posterior distributions of the parameters were obtained using a Gibbs sampler with data augmentation (Sorensen et al., 1995). After augmentation with the cow-interval liabilities, all the fully conditional posterior distributions of the parameters can be derived in closed form as described by Sorensen et al. (1995) and Sorensen and Gianola (2002). Chang (2002) gives details of the Gibbs sampling scheme applied.

Convergence diagnostics. Visual inspection of trace plots and the convergence diagnostic method of 
Table 3. Mean, SD, and percentiles of the posterior distribution of the elements $\left(g_{\mathrm{ij}}\right)$ of the $5 \times 5$ covariance matrix of the sire regression coefficients $(\mathbf{G})$ and of the herd and "cow-specific" variances $\left(\sigma_{h}^{2}\right.$ and $\left.\sigma_{p}^{2}\right)$.

\begin{tabular}{|c|c|c|c|c|c|}
\hline \multirow{2}{*}{$\begin{array}{l}\text { Covariance } \\
\text { component }\end{array}$} & \multicolumn{2}{|c|}{ Posterior } & \multicolumn{3}{|c|}{ Percentiles } \\
\hline & Mean & $\mathrm{SD}$ & $5 \%$ & $50 \%$ & $95 \%$ \\
\hline$g_{00}$ & 0.061 & 0.0179 & 0.035 & 0.059 & 0.094 \\
\hline$g_{11}$ & 0.010 & 0.0025 & 0.006 & 0.010 & 0.014 \\
\hline$g_{22}$ & 0.020 & 0.0136 & 0.002 & 0.017 & 0.046 \\
\hline$g_{33}$ & 0.007 & 0.0023 & 0.003 & 0.007 & 0.011 \\
\hline$g_{44}$ & 0.004 & 0.0019 & 0.002 & 0.004 & 0.008 \\
\hline $\begin{array}{l}g_{01} \\
g_{01}\end{array}$ & -0.018 & 0.0055 & -0.027 & -0.017 & -0.009 \\
\hline$g_{02}$ & 0.022 & 0.0143 & 0.002 & 0.020 & 0.049 \\
\hline$g_{03}$ & -0.016 & 0.0054 & -0.026 & -0.016 & -0.008 \\
\hline$g_{04}$ & -0.013 & 0.0055 & -0.023 & -0.012 & -0.005 \\
\hline$g_{12}$ & -0.011 & 0.0053 & -0.020 & -0.011 & -0.002 \\
\hline$g_{13}$ & 0.007 & 0.0021 & 0.004 & 0.007 & 0.010 \\
\hline$g_{14}$ & 0.006 & 0.0019 & 0.003 & 0.006 & 0.009 \\
\hline$g_{23}$ & -0.007 & 0.0044 & -0.015 & -0.007 & -0.001 \\
\hline$g_{24}$ & -0.008 & 0.0049 & -0.017 & -0.007 & -0.001 \\
\hline$g_{34}$ & 0.005 & 0.0017 & 0.002 & 0.005 & 0.008 \\
\hline$\sigma_{h}^{2}$ & 0.065 & 0.0044 & 0.058 & 0.065 & 0.072 \\
\hline$\sigma_{p}^{2}$ & 0.108 & 0.0079 & 0.095 & 0.108 & 0.121 \\
\hline
\end{tabular}

Raftery and Lewis (1992) were used to decide total chain length and the length of burn-in. Inferences were based on 160,000 samples, with the previous 40,000 iterations discarded as burn-in.

\section{Genetic Evaluation}

Sire evaluations. The probability of mastitis at time $t$ for a specific daughters of a given sire is given by $\Phi\left[y_{i}\right.$ $\left.+h_{j}+p_{k}+\varphi_{4}^{\prime}(t)\left(\mathbf{a}_{l}+\mathbf{s}_{m}\right)\right]$ where $\Phi($. $)$ is the standard normal distribution function. Sire evaluations obtained with the longitudinal model may be presented as curves depicting the probability of mastitis along lactation. The curve for an individual cow depends on the specific value of the systematic effects associated with the records. In order to circumvent this dependence, the required sire-specific probability curve can be approximated as $\Phi\left(\mu_{m t_{i}}\right)$, where $\mu_{m t_{i}}=\mu_{t_{i}}+\varphi_{4}^{\prime}\left(t_{i}\right) \mathbf{s}_{m}, \mu_{t_{i}}$ is the probit for time $t_{i}$, and $\varphi_{4}^{\prime}\left(t_{i}\right)$ is the $5 \times 1$ vector of Legendre covariates evaluated at time $t_{i}$. The information contained in the curve can be summarized into several single numbers that can be used for ranking and selection of sires. For example, consider the expected fraction of days without mastitis (EFD) in an arbitrary time interval $\left(t_{1}, t_{2}\right)$. This may be calculated for each sire as $E F D\left(t_{1}, t_{2}\right)=\sum_{t_{i}=t_{1}}^{t_{2}}\left[1-\Phi\left(\mu_{m t_{i}}\right)\right] /\left(t_{2}-t_{1}\right)=1-M D_{m} /\left(t_{2}-t_{1}\right)$. Here $t_{1}$ and $t_{2}$ are the first and last days of the interval, respectively, $\Phi\left(\mu_{m t_{i}}\right)$ is the probability of mastitis at $d$ $t_{i}$ for an $\underset{t_{2}}{\operatorname{nnfinite}}$ number of daughters of sire $m$, and $M D_{m}=\sum_{t_{i}=t_{1}} \Phi\left(\mu_{m t_{i}}\right)$ gives the expected number of days with mastitis in the interval from $t_{1}$ to $t_{2}$. For EFD, $\Phi($ $\left.\mu_{m t_{i}}\right)$ was computed as $\Phi\left(\mu_{t_{i}}+\varphi_{4}^{\prime}\left(t_{i}\right) \overline{\mathbf{s}}_{m}\right)$, where $\mu_{t_{i}}$, as noted earlier, is the probit for interval $t_{i} ; \overline{\mathbf{s}}_{m}$ is the $5 \times$ 1 posterior mean vector of the sire-specific regression coefficients, and $\varphi_{4}\left(t_{i}\right)$ is as before. EFD were calculated for the following time intervals: 1 ) the total $330 \mathrm{~d}$ period, $\operatorname{EFD}(-30,300) ; 2)$ from $30 \mathrm{~d}$ before to $30 \mathrm{~d}$ after calving, $\operatorname{EFD}(-30,30)$; 3) from $30 \mathrm{~d}$ before to $120 \mathrm{~d}$ after calving, $\operatorname{EFD}(-30,120)$; and 4) from $120 \mathrm{~d}$ to $300 \mathrm{~d}$ after calving, $\operatorname{EFD}(120,300)$. Also, the sire rankings from EFD were compared with those obtained from two cross-sectional threshold model analyses where mastitis was treated as a single binary trait. One cross-sectional evaluation was for the interval from $30 \mathrm{~d}$ before to $300 \mathrm{~d}$ after calving (P300), and the second was from $15 \mathrm{~d}$ before to $120 \mathrm{~d}$ after calving (P120), which is the interval used for genetic evaluation of CM in Norway. These evaluations had the form $\Phi\left(\mu+\overline{\mathbf{s}}_{m}\right)$, where $\overline{\mathbf{s}}_{m}$ is the posterior mean of transmitting ability of sire $m$ and $\mu$ is the probit corresponding to the overall mean incidence of mastitis.

Heritability and genetic correlations. The longitudinal model induces a covariance function, from which time-dependent genetic parameters can be contrived. Define the "transmitting ability at $\mathrm{d} t_{i}$ ", at the liability scale, as $\varphi_{4}^{\prime}\left(t_{i}\right) \mathbf{s}_{m}$. Then, the between-sire variance of liability to CM at $\mathrm{d} t_{i}$ can be defined $\sigma_{s}^{2}\left(t_{i}\right)=$ $\varphi_{4}^{\prime}\left(t_{i}\right) \mathbf{G} \varphi_{4}\left(t_{i}\right)$, where $\varphi_{4}^{\prime}\left(t_{i}\right)$ is as before and $\mathbf{G}$ is the covariance matrix of the sire regression coefficients. The intra-herd heritability of liability to $\mathrm{CM}$ at any $\mathrm{d} t_{i}$ of lactation can be defined as $h^{2}\left(t_{i}\right)=4 \sigma_{s}^{2}\left(t_{i}\right) /\left[1+\sigma_{p}^{2}+\sigma_{s}^{2}\right.$ $\left(t_{i}\right)$ ], and the genetic correlation between liability to CM at $\mathrm{d} t_{i}$ and $t_{j}$ can be calculated as $\rho_{G, t_{i} t_{j}}=$ 


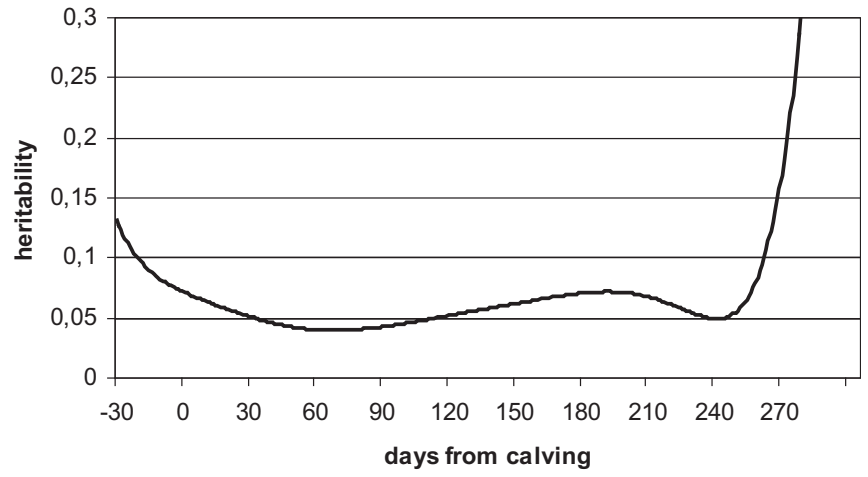

Figure 1. Heritability of liability to clinical mastitis along first lactation; $h^{2}\left(t_{i}\right)=4 \sigma_{s}^{2}\left(t_{i}\right) /\left[1+\sigma_{p}^{2}+\sigma_{s}^{2}\left(t_{i}\right)\right]$.

$\frac{\varphi_{4}^{\prime}\left(t_{i}\right) \mathbf{G} \varphi_{4}\left(t_{j}\right)}{\sqrt{\sigma_{s}^{2}\left(t_{i}\right) \times \sigma_{s}^{2}\left(t_{j}\right)}}$. The time-dependent heritabilities and genetic correlations can be inferred by replacing $\mathbf{G}$ by its posterior mean. Note that the only time-varying elements in the preceding functions are the Legendre covariates $\varphi_{4}^{\prime}\left(t_{i}\right)$ and $\varphi_{4}^{\prime}\left(t_{j}\right)$. Hence, the values of the covariates drive the relationship between the resulting genetic parameters and time, as $\mathbf{G}$ is static. Caution should be exercised when interpreting these genetic parameters, i.e., the covariance function would have a biological meaning provided $2 \varphi_{4}^{\prime}\left(t_{i}\right) \mathbf{s}_{m}$ is an adequate representation of the genotype of sire $m$ at time $t_{i}$.

\section{RESULTS AND DISCUSSION}

Mean, standard deviations and percentiles of the posterior distributions of the covariances of the sire regression coefficients and of $\sigma_{h}^{2}$ and $\sigma_{p}^{2}$ are given in Table 3.
The posterior mean of $g_{00}$ was 0.061 , and a $90 \%$ credibility set is given by the interval $(0.035$ to 0.094$)$. To the extent that the longitudinal model describes well the time-evolution of genotypes for liability to $\mathrm{CM}$, this implies that the genetic variance at calving time in the underlying scale is about 0.24 . The variances of the other regression coefficients were smaller. The evolution of posterior means of heritabilities of liability to $\mathrm{CM}$ along lactation is shown in Figure 1. Heritability ranged between 0.07 and 0.13 before calving, from 0.04 to 0.15 during the first $270 \mathrm{~d}$ of lactation, and increased sharply thereafter. Except for the last interval of lactation (270 to $300 \mathrm{~d}$ ) the contrived heritability values are in accordance with estimates from cross-sectional threshold model analyses of clinical mastitis treated as a single binary trait, which range from 0.06 to 0.12 (Lund et al., 1999; Kadarmideen, et al., 2001; Heringstad et al., 2001; 2003). The trajectory of heritability along lactation, up to $270 \mathrm{~d}$, was in agreement with Chang et al. (2001; 2002) who analyzed the same data set with an 11-variate threshold model, assuming that mastitis was a different trait in each period. It must be emphasized, however, that the steep increase in heritability observed after $270 \mathrm{~d}$ is driven primarily by the sequence of the Legendre covariates $\varphi_{4}^{\prime}(270), \varphi_{4}^{\prime}(271)$, $\ldots, \varphi_{4}^{\prime}(300)$. The disagreement with the multi-trait analyses of Chang et al. (2002) suggests that the definition of genotype in the longitudinal model approximates badly the genotype as defined in a multi-trait model, at least in this interval.

Genetic correlations between liability to $\mathrm{CM}$ at selected days of first lactation are shown in Table 4. Most correlations were larger than 0.5. Genetic correlations between adjacent days were close to 1 , but the values decreased as the interval between days increased, and the more so for early and late lactation. That is, the

Table 4. Heritability ${ }^{1}$ (on the diagonal) and genetic correlations ${ }^{2}$ (above the diagonal) for liability to clinical mastitis (CM) at selected days of first lactation.

\begin{tabular}{rllllllllllr}
\hline Day $^{3}$ & -15 & 15 & 45 & 75 & 105 & 135 & 165 & 195 & 225 & 255 & 285 \\
\hline-15 & 0.09 & 0.90 & 0.76 & 0.61 & 0.48 & 0.44 & 0.46 & 0.50 & 0.60 & 0.54 & 0.13 \\
15 & & 0.06 & 0.94 & 0.77 & 0.60 & 0.55 & 0.59 & 0.66 & 0.71 & 0.41 & -0.14 \\
45 & & & 0.04 & 0.92 & 0.79 & 0.74 & 0.74 & 0.77 & 0.80 & 0.49 & -0.09 \\
75 & & & & 0.04 & 0.96 & 0.92 & 0.88 & 0.84 & 0.86 & 0.64 & 0.10 \\
105 & & & & & 0.05 & 0.98 & 0.93 & 0.87 & 0.87 & 0.68 & 0.17 \\
135 & & & & & & 0.06 & 0.98 & 0.92 & 0.90 & 0.63 & 0.09 \\
165 & & & & & & & 0.07 & 0.98 & 0.95 & 0.54 & -0.08 \\
195 & & & & & & & & 0.07 & 0.98 & 0.49 & -0.19 \\
225 & & & & & & & & & 0.06 & 0.63 & -0.05 \\
255 & & & & & & & & & & 0.07 & 0.74 \\
285 & & & & & & & & & & & 0.41 \\
\hline
\end{tabular}

${ }^{1}$ Heritability of liability to $\mathrm{CM}$ at $\mathrm{d} t_{i}$ of lactation: $h^{2}\left(t_{i}\right)=4 \sigma_{s}^{2}\left(t_{i}\right) /\left[1+\sigma_{p}^{2}+\sigma_{s}^{2}\left(t_{i}\right)\right]$.

${ }^{2}$ Genetic correlation between liability to $\mathrm{CM}$ at $\mathrm{d} t_{i}$ and $\mathrm{d} t_{j}: \rho_{G, t_{\mathrm{i} j \mathrm{j}}}=\frac{\varphi_{4}^{\prime}\left(t^{i}\right) \mathbf{G} \varphi_{4}\left(t_{j}\right)}{\sqrt{\sigma_{s}^{2}\left(t_{i}\right) \times \sigma_{s}^{2}\left(t_{j}\right)}}$.
${ }^{3}$ From first calving. 


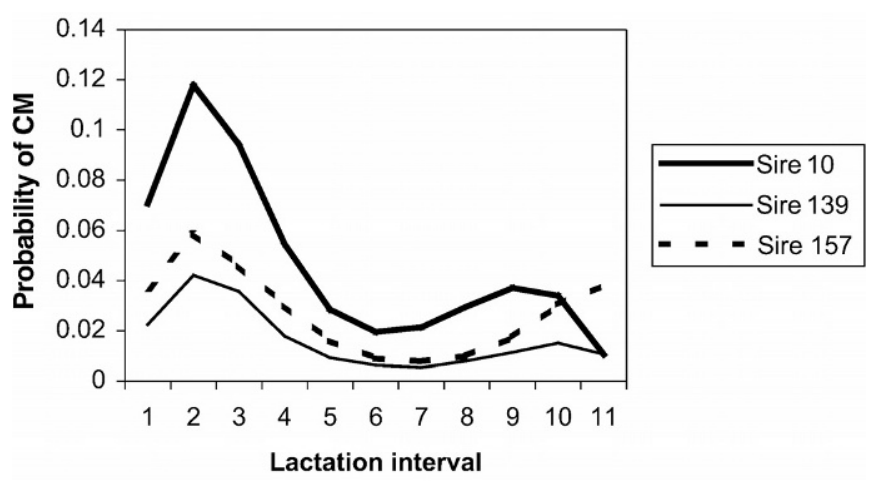

Figure 2. Probability of clinical mastitis along first lactation for the sire with the highest (sire 10) and the lowest (sire 139) peak in early lactation, and for a sire with a curve that increases in late lactation (sire 157).

genetic correlation function is more sensitive with respect to time at the edge of the time domain. Negative correlations were found only when days in late lactation, i.e., subsequent to $270 \mathrm{~d}$ after calving, were involved. In a multivariate threshold model analysis, Chang et al. $(2001 ; 2002)$ found that the posterior mean of the genetic correlations between eleven $30 \mathrm{~d}$ intervals ranged from 0.13 to 0.55 . Lund et al. (1999) estimated genetic correlations of $0.89,0.80$, and 0.67 between clinical mastitis measured in early lactation $(-10$ to $50 \mathrm{~d}$ after first calving) and in the periods 50 to $180 \mathrm{~d}, 180$ $350 \mathrm{~d}$, and 50 to $350 \mathrm{~d}$ after first calving, respectively. Genetic correlations between liability to $\mathrm{CM}$ at different stages of lactation much lower than 1 indicate that gene expression for CM varies in the course of lactation.

Figure 2 illustrates that the trajectory of the expected probability of $\mathrm{CM}$ of daughters along first lactation varies between sires. For example, sire 10 had a peaked curve, i.e., high probability of CM in early lactation, whereas sire 139 had a relatively flat curve, with a low probability of CM throughout lactation. Sire 157 would be expected to sire daughters with increased probability of CM both in early and late lactation. Variation in the trajectory of the curve suggests that sire ranking depends on the part of lactation considered. Time-dependent re-ranking of sires is illustrated in Table 5, where sire rankings based on the average expected probability of CM of daughters in each of the eleven 30 $\mathrm{d}$ intervals were calculated for the top 10 sires in interval 2 ( 0 to $30 \mathrm{~d}$ after first calving). Some sires had a consistently high ranking throughout lactation, while others ranked highly in early lactation, but had much lower ranking later on. For example, the sire ranked as the second best in interval 1 was ranked among the top 3 sires except for the last 2 intervals, where his rank was 45 and 232, respectively.

To summarize the information from the longitudinal model into a single number, EFD was computed for given intervals. The estimated probability of $\mathrm{CM}$ along lactation, for the five highest and the five lowest ranking sires based on EFD (-30, 300), is shown in Figure 3. The "best" sires had a much lower peak around calving, and a lower probability of CM throughout lactation than the lowest ranking sires.

Rank correlations between EFD from the longitudinal model and sire evaluations from the two cross-sectional models (P120 and P300) are shown in Table 6. In general, rank correlations between all sire evaluations that addressed the first part of lactation were high ( $\geq 0.89$ ). Rank correlations between EFD $(120,300)$ and other evaluations were lower (0.64 to 0.87 ). This is expected, as EFD $(120,300)$ makes use of the regression curve for the last part of lactation only. Although, rank correlations were strong, this does not imply that the same sires would be selected, especially if selection intensity is high. For example, if 10 of the 245 sires were to be selected, only 5,4 , or 7 of them would be in common if selection were based on EFD $(-30,300)$ versus EFD $(-30,30), \mathrm{P} 120$ or P300, respectively. Table 7 shows the

Table 5. Ranking of sires based on the average expected probability of mastitis for the 11 intervals of 30 $\mathrm{d}$ length each. The table shows the top 10 sires from interval 2 ( 0 to $30 \mathrm{~d}$ after calving) and their rank for the other 10 intervals.

\begin{tabular}{|c|c|c|c|c|c|c|c|c|c|c|}
\hline \multicolumn{11}{|c|}{ Sire ranking in interval } \\
\hline 1 & 2 & 3 & 4 & 5 & 6 & 7 & 8 & 9 & 10 & 11 \\
\hline 3 & 1 & 1 & 1 & 1 & 1 & 1 & 2 & 2 & 2 & 117 \\
\hline 2 & 2 & 2 & 2 & 3 & 3 & 2 & 1 & 1 & 45 & 232 \\
\hline 1 & 3 & 3 & 5 & 10 & 27 & $1 \overline{1}$ & 8 & 7 & 35 & 125 \\
\hline 5 & 4 & 7 & 9 & 17 & 23 & 43 & 35 & 27 & 20 & 79 \\
\hline 4 & 5 & 9 & 20 & 19 & 29 & 40 & 24 & 11 & 26 & 121 \\
\hline 8 & 6 & 13 & 50 & 58 & 64 & 68 & 53 & 46 & 97 & 191 \\
\hline 6 & 7 & 11 & 14 & 18 & 19 & 21 & 18 & 19 & 25 & 108 \\
\hline 11 & 8 & 4 & 6 & 4 & 5 & 5 & 3 & 3 & 72 & 217 \\
\hline 7 & 9 & 10 & 18 & 11 & 11 & 19 & 16 & 5 & 16 & 63 \\
\hline 10 & 10 & 5 & 12 & 20 & 20 & 16 & 23 & 14 & 36 & 130 \\
\hline
\end{tabular}




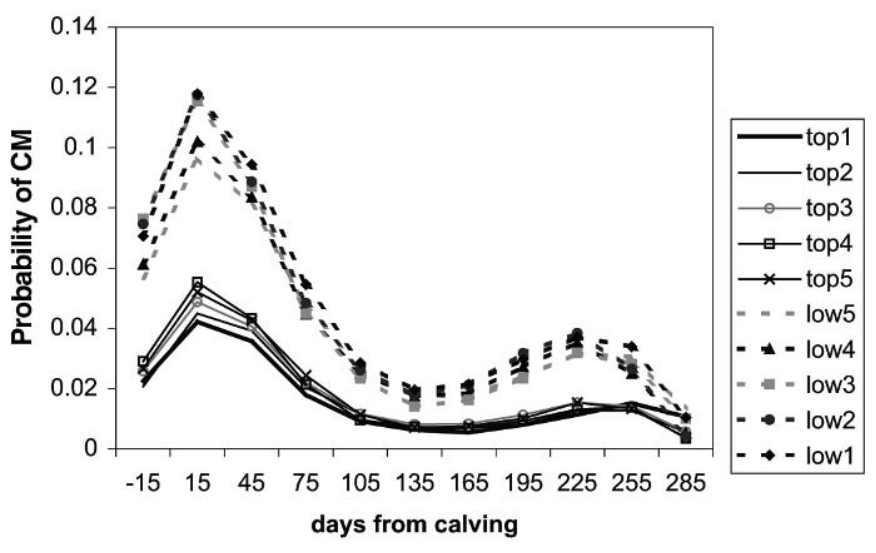

Figure 3. Probability of clinical mastitis along first lactation for the five highest ranking and the five lowest ranking sires based on the expected fraction of days without mastitis from $30 \mathrm{~d}$ before to $300 \mathrm{~d}$ after calving, $\operatorname{EFD}(-30,300)$.

top 10 sires based on EFD $(-30,300)$ and their ranking for the other sire evaluations. For some sires there was good agreement between different selection criteria. For example, the top sire based on EFD $(-30,300)$ was also the top sire for four out of the five other selection criteria. On the other hand, the sire ranked as 9 th in EFD $(-30,300)$ was ranked as 74 th based on the cross sectional model P120.

In our model the longitudinal trajectory had two time dependent sources of variation: age $\times$ season of calving classes and sire of the cow. This implies that no allowance was made for genetic variation in trajectory other than what is embedded in a sire model. Probably, part of the additional genetic variation was captured by the cow-specific effect common to all liabilities, whereas other parts may have been lumped into the residual. Extension of our model to one where individual additive genetic effects enter in the longitudinal trajectory is desirable. However, the well known "extreme category problem" of the threshold model would be exacerbated in such an implementation. More theoretical research is needed before proceeding in that direction. An additional extension of the model may include allowing for heterogeneous residual variance and a thick-tailed distribution for liability (Gianola and Sorensen, 1996).
As opposed to, e.g., milk production traits that are measured at fixed test-days, mastitis can occur at any day of lactation. In order to make sequences of binary responses, the first lactation was divided into intervals, and mastitis was scored as 0 or 1 within each interval. Here, we used eleven intervals of $30 \mathrm{~d}$ length. Further studies are needed to examine effects of the number and length of such intervals.

For illustration purposes, we used the expected fraction of days without mastitis for sire ranking. However, other criteria may be of interest. For example, more weight could be placed on mastitis in early lactation (since these cases may result in higher costs) by computing the probability of no mastitis for given intervals for each sire, and then weighting the information in some manner.

A main reason for using clinical mastitis information only from the early part of lactation, as in the current genetic evaluation in Norway, is to reduce possible sampling biases caused by culling of cows. In a longitudinal or multi-trait model (Chang et al., 2002) this is not a problem because both "incomplete lactations" and records in progress can be accommodated. Other advantages of using a longitudinal model for CM are the ability to take multiple treatments and time aspects into account, and the possibility of accounting for environmental effects peculiar to each test-interval. However, the longitudinal model may not be effective in capturing differential gene expression in different parts of lactation. This is due to the fact that the genetic or sire variance-covariance structure (e.g., the matrix $\mathbf{G}$ ) is static. The dynamics of the model are induced by the Legendre function, which, obviously, does not have a genetic component. A multiple-trait model may therefore be a more biologically sensible specification.

The results illustrate clearly that choice of the model and of the selection criteria can affect selection of sires markedly, even when rank correlations are high.

\section{ACKNOWLEDGMENTS}

Access to the data was given by the Norwegian Dairy Herd Recording System and by the Norwegian Cattle Health Service in agreement number 011.2000 by Octo-

Table 6. Rank correlations between sire evaluations from the longitudinal model, based on the expected fraction of days without mastitis (EFD) for four time intervals, and the two cross-sectional models (P120 and P300).

\begin{tabular}{llllll}
\hline & EFD $(-30,30)$ & EFD $(-30,120)$ & $\operatorname{EFD}(120,300)$ & P120 & P300 \\
\hline EFD(-30, 300) & \multirow{2}{*}{0.94} & 0.97 & 0.87 & 0.89 & 0.96 \\
EFD(-30, 30) & & 0.98 & 0.68 & 0.94 & 0.93 \\
EFD(-30,120) & & & 0.74 & 0.93 & 0.95 \\
EFD(120,300) & & & 0.64 & 0.82 \\
P120 & & & & 0.93 \\
\hline
\end{tabular}


Table 7. The 10 highest ranking sires from $\operatorname{EFD}(-30,300)$ and their ranking for sire evaluations based on $\operatorname{EFD}(-30,30), \operatorname{EFD}(-30,120), \operatorname{EFD}(120,300)$, and the two cross-sectional models P120 and P300. ${ }^{1}$

\begin{tabular}{lcccrc}
\hline EFD $(-30,300)$ & EFD $(-30,30)$ & EFD $(-30,120)$ & $\operatorname{EFD}(120,300)$ & P120 & P300 \\
\hline 1 & 1 & 1 & 6 & 1 & 1 \\
2 & 2 & 2 & 1 & 4 & 2 \\
3 & 3 & 3 & 11 & 5 & 4 \\
4 & 17 & 6 & 2 & 34 & 7 \\
5 & 4 & 4 & 5 & 35 & 8 \\
6 & 12 & 8 & 4 & 51 & 14 \\
7 & 30 & 13 & 13 & 16 & 12 \\
8 & 14 & 28 & 3 & 74 & 10 \\
9 & 51 & 10 & 25 & 37 & 24 \\
10 & 10 & & & & \\
& & 7 & 7 & 4 & 7 \\
No. of common sires & 5 & & & & \\
among top 10 & & & & & \\
\hline
\end{tabular}

${ }^{1} \mathrm{EFD}=$ expected fraction of days without mastitis.

ber 12, 2000. GENO Breeding and A.I. Association is acknowledged for providing pedigree information on sires. This work is part of the "Healthy Cow" project financed by the Research Council of Norway. Support has also been received from the Babcock Institute for International Dairy Research and Development, University of Wisconsin-Madison, by NFS grant DEB00.89742, and by grant NRICGP/USDA 99-35205-8162.

\section{REFERENCES}

Chang, Y. M., R. Rekaya, D. Gianola, B. Heringstad, and G. Klemetsdal. 2001. Correlations between clinical mastitis at different stages of lactation in Norwegian Cattle using a multivariate threshold model. J. Dairy Sci. 84 (Suppl.1):110.

Chang, Y. M., 2002. Multivariate and longitudinal models for binary data with applications to clinical mastitis in Norwegian cattle. Ph.D. diss., Univ. Wisconsin, Madison.

Chang, Y. M., D. Gianola, B. Heringstad, and G. Klemetsdal. 2002. Correlations between clinical mastitis in different periods of first lactation Norwegian Cattle using a multivariate threshold model. Pages 177-192 in Case Studies in Bayesian Statistics, Vol 6. C. Gatsonis, A. Carriquiry, A. Gelman, D. Higdon, R. Kass, D. Pauler, and I. Verdinelli ed. Springer Verlag, New York.

Gianola, D. 1982. Theory and analysis of threshold characters. J. Anim. Sci. 54:1079-1096.

Gianola, D., and D. A. Sorensen. 1996. A mixed effects threshold model with t-distributions. Page 47 in Book of abstracts of the 47th annual meeting of the EAAP. Lillehammer, Norway.
Heringstad, B., G. Klemetsdal, and J. Ruane. 2000. Selection for mastitis resistance in dairy cattle: a review with focus on the situation in the Nordic countries. Livest. Prod. Sci. 64:95-106.

Heringstad, B., R. Rekaya, D. Gianola, G. Klemetsdal, and K. A. Weigel. 2001. Bayesian analysis of liability to clinical mastitis in Norwegian Cattle with a threshold model: effects of data sampling method and model specification. J. Dairy Sci. 84:2337-2346.

Heringstad, B., R. Rekaya, D. Gianola, G. Klemetsdal, and K. A. Weigel. 2003. Genetic change for clinical mastitis in Norwegian Cattle: a threshold model analysis. J. Dairy Sci. 86: 369-375.

Jensen, J. 2001. Genetic evaluation of dairy cattle using test-day models. J. Dairy Sci. 84:2803-2812.

Kadarmideen, H. N., R. Rekaya, and D. Gianola. 2001. Genetic parameters for clinical mastitis in Holstein-Friesians in the United Kingdom: a Bayesian analysis. Anim. Sci. 73:229-240.

Lund, M. S., J. Jensen, and P. H. Petersen. 1999. Estimation of genetic and phenotypic parameters for clinical mastitis, somatic cell production deviance and protein yield in dairy cattle using Gibbs sampling. J. Dairy Sci. 82:1045-1051.

Raftery, A. L., and S. Lewis. 1992. How many iterations in the Gibbs sampler? Pages 763-774 in Bayesian Statistics. J. M. Bernando, J. O. Berger, A. P. Dawid, and A. F. M. Smith, ed. Oxford University Press.

Rekaya, R., S. L. Rodriguez-Zas, D. Gianola, and G. E. Shook. 1998. Test-day models for longitudinal binary responses: an application to mastitis in Holsteins. Page 44 in Book of abstracts 49th Annual Meeting of EAAP.

Sorensen, D. A., S. Andersen, D. Gianola, and I. Korsgaard. 1995. Bayesian inference in threshold models using Gibbs sampling. Genet. Sel. Evol. 27:229-249.

Sorensen, D., and D. Gianola. 2002. Likelihood, Bayesian, and MCMC methods in quantitative genetics. Springer-Verlag, New York.

Swalve, H. H. 2000. Theoretical basis and computational methods for different test-day genetic evaluation methods. J. Dairy Sci. 83:1115-1124. 